\title{
A FORMAÇÃO DO PEDAGOGO EM REFLEXÃO
}

\author{
Lia Machado Fiuza Fialho ${ }^{1}$ \\ Universidade Estadual do Ceará \\ http://orcid.org/0000-0003-0393-9892 \\ Francisca Genifer Andrade de Sousa ${ }^{2}$ \\ Universidade Estadual do Ceará \\ http://orcid.org/0000-0001-8280-3250
}

\section{RESUMO:}

Objetivou-se compreender como os professores do curso de Pedagogia da Universidade Estadual do Ceará (UECE) percebem a formação do pedagogo por eles desenvolvida. A pesquisa qualitativa, do tipo estudo de caso, utilizou história oral temática como instrumento de coleta de dados, o que possibilitou entrevistar oito docentes do curso de Pedagogia, vinculado ao Centro de Educação da UECE. As oralidades foram gravadas, transcritas, textualizadas e validadas para posterior análise categórica. Emergiram três categorias: Atuação docente; Formação pedagógica e saberes docente; Pensamento crítico e reflexivo. Constou-se, na compreensão dos professores, o predomínio do entendimento de que o pedagogo era prioritariamente professor da educação infantil e dos anos iniciais do ensino fundamental, invisibilizando outros importantes campos de atuação desse profissional - hospitais, empresas, sistemas sócios educativos. Valorização da formação generalista com ênfase aos aspectos pedagógicos e de uma atuação crítica e contextualizada. Discute-se que as constantes transformações no decorrer do processo formativo do pedagogo não colaboram para constituição de sua identidade como cientista da Educação.

Palavras-chave: Formação inicial. Pedagogia. Formação de professor.

\section{THE FORMATION OF THE PEDAGOGUE IN REFLECTION}

The objective was to understand how the teachers of the Pedagogy course at the Universidade Estadual do Ceará (UECE) perceive the formation of the pedagogue developed. The qualitative research, of the case study type, used thematic oral history as an instrument of data collection, which made it possible to interview eight teachers of the Pedagogy course, linked to the Education Center of the UECE. The oralities were recorded, transcribed, textualized and validated for further categorical analysis. Three categories emerged: Teaching performance; Pedagogical training and teaching knowledge; Critical and reflective thinking. In the understanding of the teachers, there was a predominance of the understanding that the pedagogue was primarily a teacher of early childhood education and of the early years of elementary school, making other important fields of activity of this professional invisible - hospitals, companies, socio-educational systems. Valuation of generalist training with emphasis on pedagogical aspects and critical and contextualized performance. It is argued that the constant changes in the course of the educator's training process do not contribute to the constitution of his identity as an education scientist.

Keywords: Initial formation. Pedagogy. Teacher training.

\footnotetext{
1 Pós-doutorada em Educação (UFPB). Professora Adjunta do Centro de Educação (UECE). Líder do Grupo de Pesquisa Práticas Educativas Memórias e Oralidades - PEMO. Editora chefa da revista Educação \& Formação do PPGE/UECE e Editora da coleção Práticas Educativas (EdUECE). Brasil. Email: lia_fialho@yahoo.com.br

2 Mestre em Educação pelo Programa de Pós-Graduação em Educação (UECE). Pesquisadora do grupo de pesquisa Práticas Educativas Memórias e Oralidades da Universidade Estadual do Ceará (PEMO/UECE). Brasil. E-mail: geniferandrade@yahoo.com.br
} 


\title{
LA FORMACIÓN DEL PEDÁGOGO EN REFLEXIÓN
}

\begin{abstract}
:
El objetivo era entender cómo los profesores del curso de Pedagogía de la Universidade Estadual do Ceará (UECE) perciben la formación del pedagogo desarrollado por ellos. La investigación cualitativa, del tipo de estudio de caso, utilizó la historia oral temática como instrumento de recopilación de datos, lo que permitió entrevistar a ocho docentes del curso de Pedagogía, vinculados al Centro de Educación de la UECE. Las oralidades se registraron, transcribieron, textualizaron y validaron para un análisis categórico adicional. Surgieron tres categorías: desempeño docente; Formación pedagógica y conocimiento docente; Pensamiento crítico y reflexivo. En la comprensión de los maestros, predominaba la comprensión de que el pedagogo era principalmente un maestro de educación de la primera infancia y de los primeros años de la escuela primaria, haciendo invisibles otros campos de actividad importantes de este profesional: hospitales, empresas, sistemas educativos asociados. Valoración de la formación generalista con énfasis en aspectos pedagógicos y desempeño crítico y contextualizado. Se argumenta que los cambios constantes en el curso del proceso de formación del educador no contribuyen a la constitución de su identidad como científico de la educación.
\end{abstract}

Palabras clave: Entrenamiento inicial. Pedagogía. Formación del profesorado.

\section{Introdução}

Desde a sua criação, na primeira metade do século XX, a Pedagogia passou por incompreensões quanto à sua finalidade, bem como pela "incerteza sobre o propósito e a função do pedagogo" (ARANTES; GEBRAN, 2014, p. 293). Libâneo (1999) aponta que essa problemática decorre das múltiplas facetas que o curso foi assumindo ao longo do tempo. Fundado para formar o técnico em educação e o professor, atualmente o pedagogo é um profissional que pode atuar em variados ambientes: hospital, empresa, universidade, escolas etc., sendo este último o principal lócus de trabalho do pedagogo (PIMENTA, 2017).

Na segunda década do século XX, a Pedagogia ainda é entendida a partir de duas vertentes: enquanto ciência da educação orientada pela investigação e pela reflexão do fenômeno educativo, concebendo o saber científico dessa área do conhecimento; e como curso formativo do profissional pedagogo, socialmente conhecido pela educação de crianças (SCHMIED-KOWARZIK, 1988; PEREIRA; RIBEIRO, 2017).

Ante a esse cenário dinâmico e complexo, por vezes dual, questiona-se o que os docentes do curso de Pedagogia da Universidade Estadual do Ceará (UECE) entendem sobre a formação do pedagogo, considerando os significados atribuídos ao processo formativo dessa categoria. Para responder a essa inquietação, desenvolveu-se uma pesquisa com o objetivo de compreender como os professores do curso de Pedagogia da UECE percebem a formação do pedagogo por eles desenvolvida.

De acordo com Costa (2015), a indefinição de como deve proceder a formação do pedagogo é histórica e acompanha toda a trajetória do curso de Pedagogia, que passou por muitas 
reformulações ao longo do tempo, o que refletiu em modificações no modo como se definiu o ser pedagogo, ultrapassando a mera instrumentalidade e voltando-se para a formação humana e valorização da racionalidade substantiva (SILVA; SILVA, 2019). Dessa maneira, a pesquisa proposta se torna relevante por permitir refletir acerca de como tem sido efetivada a formação pedagógica e quais significados são produzidos e disseminados sobre o papel do pedagogo pelos professores formadores da UECE.

Importa salientar que, independentemente do local de atuação do pedagogo, Alves, Fialho e Lima (2018) defendem que este deve assumir a responsabilidade de refletir, compreender e discutir sobre a educação na sua interface com a realidade social, sendo tarefa primordial "[...] organizar as condições para que o ensino possa realizar-se de maneira adequada" (FRANCO, 2012, p. 30). Portanto, resta oportuno lançar luz a estudos que tensionam debates acerca da formação do pedagogo (ARAÚJO; ESTEVES, 2017; DANTAS; SCHMITZ, 2016).

\section{O Curso de Pedagogia e a formação do pedagogo}

Desde a sua gênese no Brasil, em 1939, por meio do Decreto n 1.190 (BRASIL, 1939), o curso de Pedagogia é marcado pela imprecisão quanto ao seu modelo formativo e à finalidade dos profissionais formados nessa área (SAVIANI, 2008). O duplo modelo, 'licenciatura' ou 'bacharelado', distinguia os rumos de dois modelos de pedagogo: enquanto o primeiro se destinava a lecionar em sala de aula, o segundo se tornava técnico em educação para funções pedagógicas. Brzezinski (1995) assinala que essa organização curricular dual acarretava dicotomia entre o conteúdo e o método e, em decorrência, entre a teoria e a prática.

Em 1962, o parecer do Conselho Federal de Educação de nº 251 (BRASIL, 1962) manteve a estruturação das licenciaturas no esquema $3+1$, no qual se concedia o título de bacharel a quem cursasse três anos de estudos em conteúdo específico da área - fundamentos e teorias educacionais, e o título de licenciado, para atuar como professor, aos que, tendo concluído o bacharelado, cursassem mais um ano de estudos, dedicados à Didática e à Prática de Ensino. Esse modelo formativo perdurou até 1969, quando a Reforma Universitária de nº 5.540 (BRASIL, 1968) estabeleceu que a Pedagogia iria formar somente licenciados e aboliu a formação do bacharel.

Arantes e Gebran (2014, p.203) explicam que as tentativas iniciais de definir a função do pedagogo tornou a identidade desse profissional ainda mais fragilizada em decorrência da fragmentação da sua formação "diante das possibilidades das habilitações serem concluídas isoladamente umas das outras, além do fato de ser permitido a todos os licenciados, independente dos cursos, essa complementação pedagógica.” Já no final da década de 1990, os currículos 
universitários superaram essa dicotomia ao direcionaram a formação do pedagogo apenas para a licenciatura, com ênfase no espaço escolar para a atuação na educação pré-escolar e nas séries iniciais do $1^{\mathrm{o}}$ grau, hoje ensino infantil e fundamental (PINTO, 2002). No entanto, a inconsistência acerca do campo de atuação do pedagogo persiste, prejudicando a constituição de sua identidade (XEREZ, et. al., 2018).

A Lei de Diretrizes e Bases da Educação, Lei n. 9.394/96 (BRASIL, 1996), estabeleceu que o curso de Pedagogia deve ser desenvolvido em nível de graduação em instituições de ensino superior. Este deve englobar disciplinas filosóficas, científicas e técnico-pedagógicas, dada a complexidade da formação e da atuação do pedagogo (FRANCO, 2012). As Diretrizes Curriculares Nacionais $(\mathrm{DCN})$ para o curso de Pedagogia apresentam à docência como basilar para a formação do pedagogo, ainda que verse sobre a sua atuação na educação não formal (BRASIL, 2006).

Libâneo (2006), Pinto (2002), Franco (2012) e Pimenta (2017), entendem que as DCN reduzem a formação do pedagogo, pois a docência é apenas uma das áreas que o curso deve abordar, pois “[...] não há nenhuma sustentação teórica, nem pela epistemologia, nem pela tradição da teoria pedagógica, a afirmação de que a base de formação do pedagogo é a docência" (LIBÂNEO, 1999, p.30).

Os marcos históricos e legais que foram estruturando o curso de Pedagogia no Brasil e definindo a formação do pedagogo denotam que esse é um processo permeado por incertezas e por indefinições. Ultrapassando a compreensão legalista dos textos, é crucial perceber como os docentes do curso de Pedagogia compreendem e fomentam a formação do pedagogo atualmente.

\section{Metodologia}

A pesquisa adotou a abordagem qualitativa (MINAYO, 2007) porque trabalhou com as singularidades que perpassaram a compreensão dos docentes do curso de Pedagogia sobre a formação do pedagogo, ou seja, priorizou uma análise mais aprofunda que considerou as suas subjetividades. Foi do tipo estudo de caso único, pois realçou uma única universidade, a UECE, e curso, a Pedagogia. Yin (2001, p.32) defende a pertinência do estudo de caso por se tratar de "uma investigação empírica que investiga um fenômeno contemporâneo dentro do seu contexto da vida real $[\ldots] "$.

O lócus da pesquisa foi a UECE, campus Itaperi, localizado em Fortaleza, instituição de destaque no estado por ser a maior universidade estadual do Ceará em números de pedagogos 
graduados (FIALHO; SOUSA; DIAZ, 2020). Já os participantes do estudo foram os docentes do curso de Pedagogia, vinculado ao Centro de Educação (CED) da referida universidade.

O corpo docente do curso de Pedagogia da UECE era composto por 50 professores, sendo 36 efetivos e 14 substitutos. Optou-se por selecionar aproximadamente 30\% dos docentes efetivos, logo, considerando esse universo, convidou-se aleatoriamente 11 docentes para participar da pesquisa. Desses, três alegaram falta de tempo e oito consentiram colaborar, assinando o termo de consentimento livre e esclarecido. Neste, explicitava-se a temática da pesquisa, o objetivo, a forma de participação, de divulgação dos resultados etc. Foi assegurado o anonimato, por isso, adotou-se apenas as iniciais dos professores para referenciar suas falas: R.D, O.M, M.S, R.B, M.D, J.S, M.F e I.L.

A história oral temática foi utilizada como técnica de coleta de dados (MEIHY; HOLANDA, 2007), esta consiste na realização de entrevistas abertas elaboradas a partir de um projeto em história oral previamente pensado. As entrevistas foram gravadas, transcritas, textualizadas e validadas, em conformidade com a técnica de estrutura geradora do discurso (FLICK, 2009), que permitiu aos participantes ler as textualizações provenientes das suas oralidades e confirmá-las, suprimindo ou complementando informações para melhorar a compreensão do leitor.

Realizadas de maneira individual, na UECE, em abril de 2019, as entrevistas tiveram duração média de 20 minutos cada, e se centraram em quatro questionamentos básicos: 1) O que você compreende por formação pedagógica? 2) Qual a importância de formar o professor pedagogo? 3) Que aspectos a formação do pedagogo deve contemplar? e 4) Considerando o contexto educacional atual, como deve ser desenvolvida a formação do pedagogo?

Os dados foram submetidos à análise de conteúdo (BARDIN, 2009), o que oportunizou, a partir da inferência e da dedução, uma maior compreensão das narrativas. Nesse processo, foram seguidas três fases: pré-análise; exploração do material e tratamento dos resultados; e inferência e interpretação. Na primeira, as ideias iniciais foram condensadas; na fase seguinte, as transcrições foram exploradas mediante cuidadosa leitura e releitura; e, por fim, na inferência e na interpretação dos resultados, atentando-se à afinidade dos relatos, os discursos foram reunidos em grupos temáticos.

\section{Resultados e discussões}

Do processo de análise de conteúdo emergiram três categorias, a saber: 1) Atuação docente; 2) Formação pedagógica e saberes docente; e 3) Pensamento crítico e reflexivo. 
Todos os docentes apontaram o pedagogo como o profissional que é, acima de tudo, professor de crianças, conforme anunciado no relato seguinte:

[...] Por isso a importância de formar esses profissionais que são sensíveis, têm muitas habilidades para trabalhar principalmente na Educação Infantil, porque é conforme a origem do próprio nome, pedagogia quer dizer conduzir crianças, então, como o pedagogo é um ser com múltiplas habilidades, ele é importante para a educação das crianças pequenas (M.S, 22/04/2019).

A docente J.S, ao refletir sobre o campo de atuação do pedagogo concluiu que eles são importantes por dar início à escolarização formal, e acrescenta que sem eles o processo educativo seria prejudicado, uma vez que os demais professores só atuam nas séries mais adiantadas: “O licenciado em Matemática, Física, Química [...] vai entrar na nossa história da escolaridade a partir do sexto ano, e quem prepara nos anos iniciais e quem vai estar na educação infantil? É o pedagogo! Essa é a importância do pedagogo" (J.S, 26/04/2019).

A docente R.D teceu reflexões acerca das diversas áreas que o pedagogo tem acesso no decorrer do processo formativo e concluiu que todas as aprendizagens devem ser úteis à compreensão geral da educação e à instrução das crianças na Educação Infantil e nos anos iniciais do Ensino Fundamental.

Todas as contribuições das mais diversas áreas têm que possibilitar ao pedagogo, como profissional, compreender a educação como um todo e ser capaz de selecionar os conteúdos que são essenciais ao desenvolvimento da criança da Educação Infantil e do Ensino Fundamental, que é a área de atuação do pedagogo; bem como de ser capaz de as melhores metodologias, os melhores métodos para a socialização desse conhecimento selecionado (R.D, 16/04/2019).

Considerar o pedagogo como um professor para crianças é uma construção social que há muito se desenvolve (FAHEINA; ALVES, 2017; LIMA; SANTOS, 2018), no entanto, de acordo com Libâneo (2006), essa visão é ultrapassada e reducionista e se ampara no senso comum disseminado, muitas vezes, pelos próprios pedagogos, que entendem a Pedagogia apenas como o modo de ensinar, quando na realidade ela é um campo do conhecimento que trata sobre as diversas aprendizagens, ou seja, o "pedagogo é todo profissional que lida com a formação de sujeitos, seja em instituições de ensino, seja em outro lugar" (LIBÂNEO, 2006, p.215).

Essa compreensão simplista, criticada por Libâneo (2006), é um quadro problemático no campo da Pedagogia desde a sua fundação, que está longe de ser superado, pois, por mais que as DCN para o curso de Pedagogia versem sobre a atuação dos pedagogos em espaços não-escolares, a compreensão geral que esse documento transparece é a formação para a docência, 
e os currículos dos cursos tendem a seguir a mesma direção (SEVERO, 2018; PINHEIRO el. al., 2018).

Somente uma docente mencionou os espaços não escolares onde o pedagogo pode atuar, ainda assim, como as demais, parte do princípio de que a formação do pedagogo deve focar na docência. Explicando que o espaço não formal é para ser pensado quando não houver interesse do aluno pela docência na escola regular: "Você pode ser, se não quiser ser professora, gestora de escola, uma coordenadora pedagógica, você pode trabalhar com adultos, você pode trabalhar com jovens, enfim, você pode trabalhar em um ambiente escolar e em um ambiente não escolar (I.L, 26/04/2019).

Importa ressaltar que a percepção dos professores está refletida no currículo do curso de Pedagogia da UECE, pois não há disciplinas, seja obrigatória ou optativa, que abordem sobre a pedagogia hospitalar, empresarial, em espaços socioeducativos, dentre outros. Igualmente, Severo (2018), ao realizar estudo objetivando investigar como tem sido encaminhada a formação dos pedagogos no Brasil, a partir da análise dos projetos de curso de vinte universidades do país, averiguou que "há elementos que demonstram uma clara tendência em centralizar o magistério escolar na discussão sobre os princípios norteadores e a finalidade que justifica o curso de Pedagogia" (SEVERO, 2018, p.10).

Sobre esse assunto, Saviani (2007) leciona que há uma incapacidade histórica de reflexão sobre o que se trata a dimensão pedagógica, que é sempre limitada à docência, quando na realidade ela ultrapassa esse ambiente e permeia todas as situações onde seja possível ser desenvolvido ensino e aprendizagem.

\section{Categoria 2 - Formação pedagógica e saberes docente}

A formação pedagógica foi apontada como primordial, pois os docentes a compreenderam como aquela que instrui o licenciando e fundamenta a prática docente, sendo crucial para constituir o professor.

Formação pedagógica é muito relacionada à postura docente em sala de aula. É ela quem define todo o processo, o tempo dispendido para a formação das crianças [...]. É a dimensão pedagógica que irá permitir que haja reflexão acerca do ato educativo. Eu formo pedagogicamente o pedagogo quando estímulo a repensar as suas ações em sala de aula. É para isso que serve a formação pedagógica, para melhorar a prática através da reflexão sobre ela (M.S, 22/04/2019).

Com base nesse relato, a dimensão pedagógica pode ser entendida como um processo que articula o conteúdo científico e a aprendizagem prática, que "possibilita a qualificação da prática 
docente" (CORRÊA; RIBEIRO, 2013, p.322). Afinal, o pedagogo, na condição de professor, deve dominar os conteúdos disciplinares e pedagógicos (SMYTH; HAMEL, 2016). A docente R.D distingue a formação do pedagogo em duas áreas principais: a técnica e a metodológica. A técnica é relacionada aos conteúdos, e a metodológica aos meios empregados para gerir a aprendizagem.

A parte da competência técnica do pedagogo engloba primeiro o conhecimento específico da área para qual está sendo formado. Então, ele tem que compreender o conteúdo específico. O segundo aspecto é o metodológico, porque não basta ele se apropriar do conteúdo, ele tem que se apropriar dos métodos, das metodologias e dos recursos necessários para que ele possa socializar os conteúdos com as crianças, com os adolescentes, de acordo com a série, de acordo com as condições subjetivas (R.D, 16/04/2019).

A compreensão acerca da necessidade da articulação da teoria com a prática é explanada por todos os docentes participantes do estudo. Corrêa e Ribeiro (2013, p.321) comunga com essa compreensão ao inferir que primeiro o professor deve ter uma formação pautada nos conteúdos que irá lecionar e, na sequência, “[...] uma formação didático-pedagógica em que se estabeleça a ligação dos princípios gerais que regem as relações entre o ensino e a aprendizagem." Para isso, a formação do pedagogo, além do aspecto pedagógico, deve contemplar outros saberes inerentes à prática em sala de aula, que são adquiridos ao longo de toda a vida e ampliados com as formações continuadas (MORORÓ, 2017).

Por saber docente, entende-se o conjunto de conhecimentos científicos e epistemológicos necessários à atuação em sala de aula adquiridos por diversos meios: pela experiência, pela apreensão dos conteúdos, pelo currículo (TARDIF, 2002). Sobre esse assunto, no entanto, as docentes entrevistadas se referiram, quase exclusivamente, aos saberes curriculares do curso de Pedagogia, invisibilizando os demais, o que pode acarretar a ingerência tecnocrata à construção da autonomia profissional (BEGO, 2016; ALVES; FIALHO, 2019). Na contramão, compreendiam que o pedagogo deveria ter domínio das múltiplas facetas da educação, mediante uma formação diversificada, englobando as diversas áreas do conhecimento. J.S explica que a

Pedagogia tem como objetivo compreender a educação. Então, a formação do pedagogo deve proporcionar aos estudantes de pedagogia, ao futuro pedagogo, uma compreensão geral sobre o fenômeno educativo nas suas mais variadas relações. Então, a educação, a partir da contribuição da Filosofia da Educação, da Psicologia da Educação, da História da Educação e assim sucessivamente. [...] Assim como é necessário que o pedagogo compreenda o funcionamento da escola como um todo (J. S, 26/04/2019). 
O.M comunga a compreensão de J.S e acrescenta:

O pedagogo deve dominar vários conhecimentos, então a formação dele deve englobar [...] os conhecimentos pedagógicos e da didática, além daqueles das disciplinas que ele pode ministrar na escola. É muita coisa, é um profissional muito amplo, uma formação muito complexa, no meu entendimento (O.M, 17/04/2019).

Somente uma das entrevistadas não listou a diversidade de áreas que devem compor o curso de Pedagogia. Essa docente destacou apenas três dimensões entendidas como essenciais: a reflexiva, a ética e a pedagógica: "a reflexiva, porque esse profissional deve estar sempre refletindo sobre a sua prática, a ética porque ele assume um compromisso, e a pedagógica para que ele seja capaz de não somente dominar a teoria, mas de promover e de gerir situações de aprendizagem" (M.D, 25/04/2019).

Pimenta (2017, p.24) explica que "os cursos apresentam um grande leque com inúmeras e diversificadas disciplinas, possivelmente para preparar o pedagogo para atuar nas diversas áreas, suprir a formação anteriormente realizada pelas antigas habilitações." No entanto, ainda atualmente, o pedagogo "precisa dos conhecimentos da ciência pedagógica, fundamentos da docência, assim como precisa dos conhecimentos disciplinares daquilo que vai ensinar." (FRANCO, 2012, p. 30).

Estruturada a formação do pedagogo nesses moldes, disciplinas generalistas e pedagógicas, Pimenta (2017) acredita que o resultado são profissionais sem a qualidade necessária nem como pedagogo que se dedica aos estudos da ciência da educação, nem como docente. Faheina e Alves (2017, p.347) defendem que "estas múltiplas dimensões [...] projetam a composição de uma base curricular de curso complexa, fragmentada e ineficiente".

\section{Categoria 3 - Pensamento crítico e reflexivo}

Ao versar sobre os aspectos que a formação do pedagogo deve contemplar a partir da conjuntura brasileira atual, seis docentes chamaram atenção para o desenvolvimento da postura crítica e reflexiva acerca das relações sociais e políticas, essenciais para uma prática docente contextualizada (LARA, 2016). Genú (2018) comunga com a importância e a necessidade de o docente adotar uma ação pedagógica crítica ante uma epistemologia da práxis pedagógica.

Situando a formação e a atuação do pedagogo no cenário contemporâneo, R.D (16/04/2019) considera que "hoje a gente vive uma situação muito preocupante em todos os aspectos. Nós temos uma situação de desconstituição dos direitos sociais: saúde, educação, previdência." Ante 
a essa realidade, as docentes apontaram a criticidade como elemento basilar na formação do pedagogo (ALMEIDA; SOARES, 2010), justamente para que esses profissionais possam lutar pelos seus direitos e pela justiça social, sendo resistência, inclusive, contra as injustiças que a categoria docente vem sofrendo.

Especialmente a formação do pedagogo na Pedagogia deveria levar em conta todo esse contexto que a gente está vivendo e preparar não só para fazer um enfrentamento contra a retirada dos seus direitos, como também fazer um enfrentamento contra esse processo de desvalorização que a Educação e os professores estão vivendo. Então, mais do que nunca, eu penso que é necessária uma formação crítica e não o contrário, que é o que esse Governo quer (M.D, 25/04/2019).

Nota-se, portanto, que os professores aferiram importância para uma formação contextualizada que fomentasse possibilidade para formação da criticidade com vistas ao empoderamento do profissional pedagogo, para habilitá-lo a intervir na sociedade, modificando-a para o alcance de mais justiça social e valorização profissional. R.B explica que a formação do pedagogo deve contemplar duas dimensões principais: o conhecimento teórico e o despertar da consciência crítica. Nesse segundo campo, é imprescindível a formação política, “[...] que deve acontecer desde cedo, que é para ele se compreender enquanto ser político, para ele poder ver a política em sentido amplo, no sentido de que, quando você está participando, quando você se preocupa com a realidade, você está sendo político" (R.B, 22/04/2019).

Saviani (2007) leciona em congruência com o que postulam os professores citados, pois, ao compreender a Pedagogia como área do conhecimento que visa à compreensão das situações educativas, infere que ela se trata de uma ciência, sendo o pedagogo um cientista da educação. Por isso, a formação desse profissional não pode se restringir à instrumentalização técnica e metodológica, mas deve, também, considerar o desenvolvimento da criticidade através da reflexão do seu contexto. Dessa forma, "o pedagogo assume um papel importante como profissional da educação pela relevância política e social que comporta, pois seu objetivo é pautado no desenvolvimento da formação humana" (COSTA, 2015, p. 25708).

R.D acrescenta que "[...] a educação tem que ser política e crítica para preparar os futuros professores, professoras e estudantes como tais para fazer um enfrentamento e não permitir que a educação viva um retrocesso" (R.D, 16/04/2019). Esse raciocínio é entendido por essa docente como um compromisso social a ser desenvolvido no decorrer da formação por intermédio da instrução técnica, pedagógica e da compreensão do contexto e das relações sociais, para que se possa formar sujeitos também críticos e conscientes sobre o seu meio. Afinal, somente quando 
o pedagogo se apropria desses elementos há condições para efetivar a transformação social e a emancipação do indivíduo (SAVIANI, 2007).

Para M.S, esse modelo formativo torna-se possível quando o estudante de Pedagogia é instigado a refletir sobre a prática docente através da ação-reflexão-ação. Sem esse movimento, denominado práxis, “a formação será insuficiente em todos os aspectos, porque nem o profissional será capaz de fazer um bom trabalho em sala de aula e nem contribuirá para aprimorar o campo da Pedagogia enquanto ciência da educação" (M.S, 22/04/2019).

Franco (2012) assevera que a formação embasada pela práxis considera o indivíduo como ser reflexivo e apto para interferir no seu meio. Assim, “as transformações das práticas docentes só se efetivam à medida que o professor amplia sua consciência sobre a própria prática [...], o que pressupõe os conhecimentos teóricos e críticos sobre a realidade" (FRANCO, 2012, p.14). Portanto, a instrumentalização do pedagogo para a criticidade deve ser um dos compromissos do curso de Pedagogia na atualidade.

No que tange a esse assunto, Libâneo (2006) nota que os cursos de Pedagogia do Brasil sentem dificuldade para se atualizar, parecendo sempre estagnados no tempo e em discordância com as transformações e com as exigências sociais. Nesses moldes, "os problemas e dilemas continuam, persistem velhos preconceitos, mantém-se apego a teses ultrapassadas, às vezes com o frágil argumento de que são conquistas históricas" (LIBÂNEO, 2006, p.17). Tal compreensão estruturada historicamente dificulta uma educação emancipadora, crítica, libertária e democrática (VASCONCELOS; FIALHO; LOPES, 2018).

\section{Considerações finais}

A pesquisa partiu de uma inquietação sobre o que os docentes do curso de Pedagogia da UECE entendiam sobre a formação do pedagogo, logo, objetivou compreender como os referidos professores percebiam a formação do pedagogo por eles desenvolvida no contexto educacional atual.

Para contemplar o escopo proposto, realizou-se uma pesquisa qualitativa, do tipo estudo de caso, que utilizou a história oral temática como técnica de coleta de dados, com oito docentes do curso de Pedagogia da UECE. As narrativas, uma vez submetidas à análise de conteúdo, resultaram na elaboração de três categorias temáticas: Atuação docente, Formação pedagógica e saberes docente, e Pensamento crítico e reflexivo.

Constatou-se que os docentes percebiam o pedagogo, principalmente, como professor da educação infantil e dos anos iniciais do ensino fundamental, campo mencionado por todos os 
entrevistados para a atuação do pedagogo. Portanto, as narrativas dos docentes explicitaram que a graduação em Pedagogia deveria privilegiar a docência para crianças, o que desprivilegiava os outros ambientes onde esse profissional poderia exercer as suas atividades profissionais. $\mathrm{Na}$ contramão, por vezes, os pedagogos eram compreendidos como sujeitos críticos e responsáveis por possibilitar empoderamento do estudante para que estes se tornassem reflexivos e adotassem uma práxis contextualizada convergente com a luta pela justiça social.

Ante à reserva de mercado para o pedagogo atuar nas séries iniciais da escolarização, este espaço era priorizado, e o ambiente não formal ficou invisibilizado, de tal forma que sequer havia disciplinas obrigatórias ou optativas para discutir a educação em contexto não escolar no curso de Pedagogia da UECE. Com efeito, os docentes acreditavam que a formação do pedagogo era de natureza ampla e complexa, e que deveria abarcar conhecimentos generalistas das diversas áreas do conhecimento, a exemplo da Filosofia, da História, da Sociologia e da Psicologia, entendidas como saberes docentes curriculares imprescindíveis à formação de qualidade do pedagogo.

Desses campos, a formação pedagógica, definida como essencial para constituir o professor, foi apontada como uma das mais importantes, uma vez que o pedagogo era percebido pelos docentes entrevistados como aquele profissional que é, por princípio, educador de crianças, devendo este se apropriar de conhecimentos plurais e das múltiplas metodologias para mediar a aprendizagem. No entanto, discutiu-se que essa formação inicial generalista ampliada por um conhecimento mais especializado do campo pedagógico não contempla uma formação adequada, nem para o pedagogo assumir com destreza uma sala de aula, nem para capacitá-lo para atuar nos ambientes não formais de aprendizagem, tais como hospitais, empresas, sistemas sócio educativos e prisionais etc.

Os professores formadores destacaram que o pedagogo, estando imerso em uma conjuntura de ameaça aos direitos sociais, especialmente de injustiças contra a classe docente, deve ser formado criticamente para o exercício da cidadania em resistência às propostas que visam a retirada de direitos da sua categoria. Visto como agente, cujo compromisso deve ser também a transformação social por meio da emancipação humana, o pedagogo deve ser formado com base na criticidade para que possa, assim, atuar na sua realidade.

Reflete-se que as constantes transformações no decorrer do processo formativo do pedagogo não colaboram para uma clareza acerca da sua responsabilidade como cientista da Educação, gerando uma incapacidade histórica de reflexão sobre o que se trata a dimensão pedagógica, reduzindo-a à docência em sala de aula, ainda que ela ultrapasse esse ambiente e possa ser desenvolvida em todas as situações onde seja possível ser produzido o ensino e a 
aprendizagem. Por isso, alguns pedagogos possuem dificuldade de constituir uma identidade docente consoante à ciência pedagógica, pois ainda há quem acredite que o pedagogo deve ser formado para atender às exigências da sociedade à educação, ou seja, do mercado de trabalho.

Pondera-se que esse estudo, por sua natureza qualitativa, descarta a possibilidade de generalização, já que abarca uma quantidade diminuta de docentes do curso de Pedagogia de uma única universidade cearense. Não obstante, torna-se relevante por possibilitar ampliar o entendimento a respeito da formação do pedagogo nos tempos atuais, além de tensionar reflexões acerca da Pedagogia em suas diferentes dimensões e feições na condição de ciência da Educação.

\section{Referências}

ALMEIDA, M. S.; SOARES, S. R. Docência universitária, inovando através do ensino com pesquisa. Plurais: revista multidisciplinar. v.1. n. 2, p.175-187, 2010. Disponível em: $<\underline{\text { ht- }}$ tps://www.revistas.uneb.br/index.php/plurais/article/view/875>. Acesso em: Acesso em: 18 jan. 2020.

ALVES, F. C.; FIALHO, L. M. F. Currículo na educação infantil: O que pensam os professores? Práxis educacional, v. 15, p. 251-272, 2019. Disponível em: $<\underline{\text { http://periodicos2.uesb.br/ }}$ index.php/praxis/index >. Acesso em: 18 jan. 2020.

ALVES, F. C.; FIALHO, L. M. F.; LIMA, M. S. L. Formação em pesquisa para professores da educação básica. Revista Tempos e Espaços em Educação, v. 11, n. 27, p. 285-300, 2018. Disponível em: $<$ https://seer.ufs.br/index.php/revtee/article/view/8582>. Acesso em: 18 jan. 2020.

ARANTES, A; GEBRAN, R. O curso de Pedagogia e o processo de formação do pedagogo no Brasil: percurso histórico e marcos legais. Holos, v.30, n.6, 2014. Disponível em: $<\underline{\text { http:// }}$ www2.ifrn.edu.br/ojs/index.php/HOLOS/article/view/1643>. Acesso em: 12 abr. 2020.

ARAÚJO, R. M.; ESTEVES, M. M. A formação docente, inicial e contínua, para o trabalho com adultos em Portugal: o olhar dos professores. Educação \& Formação, v. 2, n. 4 jan./abr., p. 18-35, 2017. Disponível em: $<$ https://revistas.uece.br/index.php/redufor/article/ view/121 >. Acesso em: 12 abr. 2020.

BARDIN, L. Análise de conteúdo. 3. ed. Lisboa: 70, 2009.

BEGO, A. Políticas públicas e formação de professores sob a perspectiva da racionalidade comunicativa: da ingerência tecnocrata à construção da autonomia profissional. Educação \& Formação, v. 1, n. 2 mai./ago., p. 3-24, 2016. Disponível em: < $\underline{\text { https://revistas.uece.br/index. }}$ php/redufor/article/view/98>. Acesso em: 18 jan. 2020.

BRASIL. Congresso Nacional. Lei 5.540 de 28 de novembro de 1968. Fixa normas de organização e funcionamento do ensino superior e sua articulação com a escola média, e dá outras providências. Diário Oficial da União, Brasília, DF, 03 dez. 1968. Disponível em: $<\underline{\text { http:// }}$ www.planalto.gov.br/ccivil 03/Leis/L5540.htm>. Acesso em: 12 abr. 2020. 
BRASIL. Decreto-lei n ${ }^{0}$ 1.190, de 4 de abril de 1939. Dá organização à Faculdade Nacional de Filosofia, 1939.

BRASIL. Lei 9.394 de 20 de dezembro de 1996. Estabelece as diretrizes e bases da educação nacional, 1996.

BRASIL. Ministério da Educação. Conselho Federal de Educação. Parecer n 261/62. Currículo mínimo e duração do curso de Pedagogia. Relator: Valnir Chagas. Brasília, DF, no 11, p. 59-65, 1962.

BRASIL. Resolução CNE/CP n.1 de 15 de maio de 2006. Institui as Diretrizes Curriculares Nacionais para o curso de Pedagogia, 2006.

BZEZINSK, I. Pedagogia, pedagogos e formação de professores: busca e movimento. São Paulo: Papirus, 1996.

CORRÊA, G. T; RIBEIRO, V. M. B. A formação pedagógica no ensino superior e o papel da pós-graduação stricto sensu. Educação e Pesquisa. v. 39, n. 2, São Paulo, 2013.

COSTA, R. A. R. Identidade do pedagogo: formação e atuação. In: XII Congresso Nacional de Educação (EDUCERE). Anais... Paraná, 2015. p. 25708-25720.

DANTAS, C.; SCHMITZ, H. A formação do pedagogo com vistas à sua atuação em ambientes empresariais. Educação \& Formação, v. 1, n. 1, jan./abr., p. 124-139, 2016. Disponível em: $<$ https://revistas.uece.br/index.php/redufor/article/view/95> . Acesso em: 12 abr. 2020.

FAHEINA, E. F. A; ALVES, F. T. O. O curso de Pedagogia do Vale do Maranguape no contexto das atuais diretrizes curriculares nacionais. Revista Espaço do Currículo, v. 10, n. 2, 2017.

FIALHO, L. M. F.; SOUSA, N. M. C.; DIAZ, J. M. H. Rosa Maria Barros Ribeiro: memórias da trajetória formativa para docência. Revista Cocar, v. 8, p. 371-387, 2020. Disponível em:

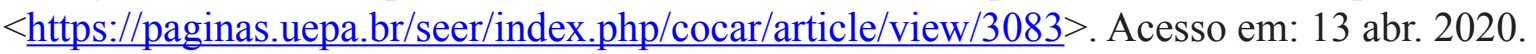

FLICK, U. Introdução à pesquisa qualitativa. 3. ed. Porto Alegre: Artmed, 2009.

FRANCO, M. A. R. S. Pedagogia e prática docente. São Paulo: Cortez, 2012.

GENÚ, M. A abordagem da ação crítica e a epistemologia da práxis pedagógica. Educação \& Formação, v. 3, n. 9 set/dez, p. 55-70, 2018. Disponível em: <https://revistas.uece.br/index. php/redufor/article/view/856 $>$. Acesso em: 18 jan. 2020.

LARA, A. M. Políticas de redução da desigualdade sociocultural. Educação \& Formação, v. 1, n. 3 set./dez., p. 140-153, 2016. Disponível em: < https://revistas.uece.br/index.php/redufor/ article/view/118 >. Acesso em: 18 jan. 2020.

LIBÂNEO, J. C. Pedagogia e pedagogos, para quê?. 2. ed. São Paulo: Cortez, 1999.

LIBÂNEO, J. C. Pedagogia e pedagogos: inquietações e buscas. Curitiba: Editora da UFPR, n. 17, 2006. 
LIMA, J.; SANTOS, G. Valores, educação infantil e desenvolvimento moral: concepções dos professores. Educação \& Formação, v. 3, n. 8, p. 153-170, 2018. Disponível em: <https:// revistas.uece.br/index.php/redufor/article/view/275>. Acesso em: 05 abr. 2020.

MEIHY, J. C. S. B; HOLANDA, F. História oral: como fazer, como pensar. São Paulo: Contexto, 2007.

MINAYO, M.C. Pesquisa social: teoria, método e criatividade. 25. ed. Petrópolis: Vozes, 2007.

MORORÓ, L. A influência da formação continuada na prática docente. Educação \& Formação, v. 2, n. 4 jan./abr., p. 36-51, 2017. Disponível em: < $\underline{\text { https://revistas.uece.br/index.php/ }}$ redufor/article/view/122>. Acesso em: 18 jan. 2020.

PEREIRA, A.; RIBEIRO, C. S. A culpabilidade pelo fracasso escolar e a interface com os "problemas de aprendizagem" em discurso. Educação \& Formação, v. 2, n. 5 mai./ago., p. 95-110, 2017. Disponível em: <https://revistas.uece.br/index.php/redufor/article/view/138>. Acesso em: 18 jan. 2020.

PIMENTA, S. G. et al. Os cursos de licenciatura em pedagogia: fragilidades na formação inicial do professor polivalente. Educação e Pesquisa. v. 43, n. 1, p.15-30, 2017. Disponível em: < https://doi.org/10.1590/s1517-9702201701152815> . Acesso em: 13 abr. 2019.

PINHEIRO, M. N. S.; RODRIGUES, T. A.; MARANHÃO, A. L. N.; FIALHO, L. M. F. Formação de professores para a Educação Infantil e séries iniciais do ensino fundamental: reflexões sobre a polivalência. Revista Internacional de Formação de Professores, v. 3, p. 401-416, 2018. Disponível em: $<$ https://periodicos.itp.ifsp.edu.br/index.php/RIFP/index Acesso em: 13 abr. 2020.

PINTO, U. A. O pedagogo escolar: avançando no debate a partir da experiência desenvolvida nos cursos de complementação pedagógica. In: PIMENTA, S. G. (Org.). Pedagogia e pedagogos: caminhos e perspectivas. São Paulo: Cortez, 2002. p. 153-198.

SAVIANI, D. História das ideias pedagógicas no Brasil. Campinas: Autores associados, 2007.

SAVIANI, D. A Pedagogia no Brasil. São Paulo: Autores associados, 2008.

SCHMIED-KOWARZIK. Pedagogia dialética de Aristóteles a Paulo Freire. 2. ed. São Paulo: Brasiliense, 1988.

SEVERO, J. L. R. L. Perspectivas curriculares sobre a formação do pedagogo para a educação não escolar. Educação em Revista, v. 34, 2018. Disponível em < $\underline{\text { http://www.scielo. }}$ br/scielo.php?pid $=\mathrm{S} 0102-46982018000100124 \&$ script $=$ sci abstract\&tlng $=\mathrm{pt}>$. Acesso em 12 abr. 2019.

SILVA E, S.; SILVA, G. P. Formação humana e racionalidade substantiva: resistência à formação instrumental. Plurais: revista multidisciplinar. v.4. n. 3, p.115-131, 2019. Disponível em: $<$ https://www.revistas.uneb.br/index.php/plurais/article/view/7785/5062>. Acesso em: 18 jan. 2020. 
SMYTH, E.; HAMEL, T. The history of initial teacher education in Canada: Québec and Ontario. Educação \& Formação, v. 1, n. 1 jan./abr., p. 88-109, 2016. Disponível em: $<\underline{\text { https:// }}$ revistas.uece.br/index.php/redufor/article/view/93 $>$. Acesso em: 18 jan. 2020.

TARDIF, M. Saberes docentes e formação profissional. Petrópolis: Vozes, 2002.

VASCONCELOS, J. G.; FIALHO, L.; LOPES, T. M. Educação e liberdade em Rousseau. Educação \& Formação, v. 3, n. 8 mai./ago., p. 210-223, 2018. Disponível em: <https:// revistas.uece.br/index.php/redufor/article/view/278>. Acesso em: 18 jan. 2020.

XEREZ, A. S. P.; FIALHO, L. M. F.; CASTRO, F. M. F. M.; MARQUES, J. L. M. Formação pedagógica e constituição da identidade docente. Intermeio, v. 24, p. 211-229-229, 2018. Dis-

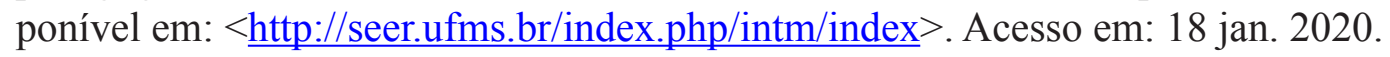

Yin, R. K. Estudo de caso: planejamento e métodos. Tradução Daniel Grassi. 2. ed. Porto Alegre: Bookman, 2001.

Recebido em: 20 de outubro de 2021.

Publicado em: 06 de dezembro de 2021. 